\title{
Probabilistic Structural Health Monitoring of the Orbiter Wing Leading Edge
}

\author{
Keng C. Yap ${ }^{1}$, Ph.D. \\ Boeing Space Exploration, Houston, TX 77059 \\ Jesus Macias $^{2}$ \\ United Space Alliance (USA), Houston, TX 77058
}

\author{
Mohamed Kaouk ${ }^{3}$, Ph.D., Tammy L. Gafka ${ }^{3}$, Justin H. Kerr ${ }^{4}$, Ph.D. \\ National Aeronautics and Space Administration (NASA), Houston, TX 77058
}

\begin{abstract}
A structural health monitoring (SHM) system can contribute to the risk management of a structure operating under hazardous conditions. An example is the Wing Leading Edge Impact Detection System (WLEIDS) that monitors the debris hazards to the Space Shuttle Orbiter's Reinforced Carbon-Carbon (RCC) panels. Since Return-to-Flight (RTF) after the Columbia accident, WLEIDS was developed and subsequently deployed on board the Orbiter to detect ascent and on-orbit debris impacts, so as to support the assessment of wing leading edge structural integrity prior to Orbiter re-entry. As SHM is inherently an inverse problem, the analyses involved, including those performed for WLEIDS, tend to be associated with significant uncertainty. The use of probabilistic approaches to handle the uncertainty has resulted in the successful implementation of many development and application milestones.
\end{abstract}

\section{Nomenclature}

$G_{\max }=$ Maximum acceleration response

$G_{r m s}=$ Root-mean-square of acceleration response

$\delta \quad=$ Logarithmic decay

$P \quad=$ Damage probability

$P_{I} \quad=$ Probability of impact

$P_{C} \quad=$ Joint probability of critical damage

$P_{C / I}=$ Conditional probability of critical damage given an impact has occurred

$P_{M} \quad=$ Probability of multi-sensor corroboration being stronger than model experience

$P_{F} \quad=$ Probability of multi-sensor corroboration being weaker than flight experience

$r_{\text {diag }}=$ Diagonal corroboration ratio of multi-sensor response

$r_{\text {horz }}=$ Horizontal corroboration ratio of multi-sensor response

$\lambda_{\text {sen }}=$ Sensor configuration test scaling factor

$\lambda_{\text {pan }}=$ RCC panel-to-panel test scaling factor

$\lambda_{t s t}=$ Test article boundary condition scaling factor

$\lambda_{\text {mea }}=$ Test measurement scaling factor

$\lambda_{\text {dam }}=$ Damage- $G_{\max }$ correlation factor

$d \quad=$ Damage size (inch)

\footnotetext{
${ }^{1}$ Project PI \& Technical Lead, Flight Loads \& Dynamics, Boeing Defense, Space \& Security (BDS), Keng.C.Yap@Boeing.com

2 Subsystem Engineer, Vehicle \& Systems Analysis, USA Orbiter Element, Jesus.Macias@USA-SpaceOps.com

${ }^{3}$ Project Manager, Structures \& Dynamics Branch, NASA-JSC, Mohamed.Kaouk@NASA.gov, Tammy.L.Gafka@NASA.gov

${ }^{4}$ Senior Project Manager, Space Shuttle Orbiter Project Office, NASA-JSC, Justin.H.Kerr@NASA.gov
} 


\section{Introduction}

$\mathrm{E}^{\mathrm{n}}$ ngineering risk management provides a means to ensure the long term operational viability of structures, particularly amid changing structural characteristics, operating environment, and functional requirements. To mitigate risk, preventative measures can be taken to minimize the structure's vulnerability to its hazardous environment via design changes, structural reinforcement, environment changes, and hazard avoidance or shielding. However, hazard prevention alone may not be economically feasible to eliminate the risk of operating a structure over its entire design life. In which case structural health monitoring (SHM) can be used to manage the residual risk of potential adverse consequences by assessing the change in mechanical properties that reflect the structure's health condition (Ref. 1-6), or by detecting the hazard events that potentially threaten the structure's integrity (Ref. 7-8). The Space Shuttle Columbia re-entry breakup was caused by External Tank (ET) foam debris release from the left bipod ramp and subsequent impact on the port wing leading edge during ascent (Figure 1a). The accident investigation found brittle failure of the Reinforced Carbon-Carbon (RCC) panel upon foam impact under known and possible conditions experienced during Columbia flight STS-107 (Figure 1b). Following the accident, the debris hazard was significantly reduced by the ET foam improvements, but not completely eliminated. The Wing Leading Edge Impact Detection System (WLEIDS) was developed under the Shuttle Program's Return-to-Flight (RTF) initiative to better monitor the debris threat to the Orbiter. The operational concept of the SHM system is that risk mitigating action to avoid loss of vehicle and crew can take place on-orbit between the time of detection and the time of re-entry. As SHM is inherently an inverse problem, a detected modality may not precisely characterize the particular source of fault condition or hazard event. Hence, analyses involved in SHM tend to be associated with significant uncertainty. Over the course of WLEIDS operations, the use of probabilistic approaches to handle the uncertainty has resulted in the successful implementation of many development and application milestones.

a) Columbia Foam Strike

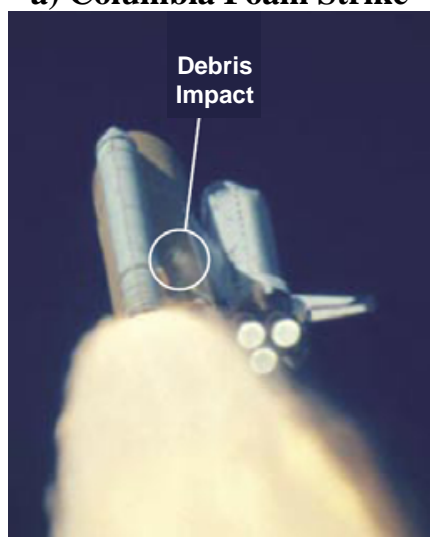

b) Gaping Hole from Ballistic Impact Test

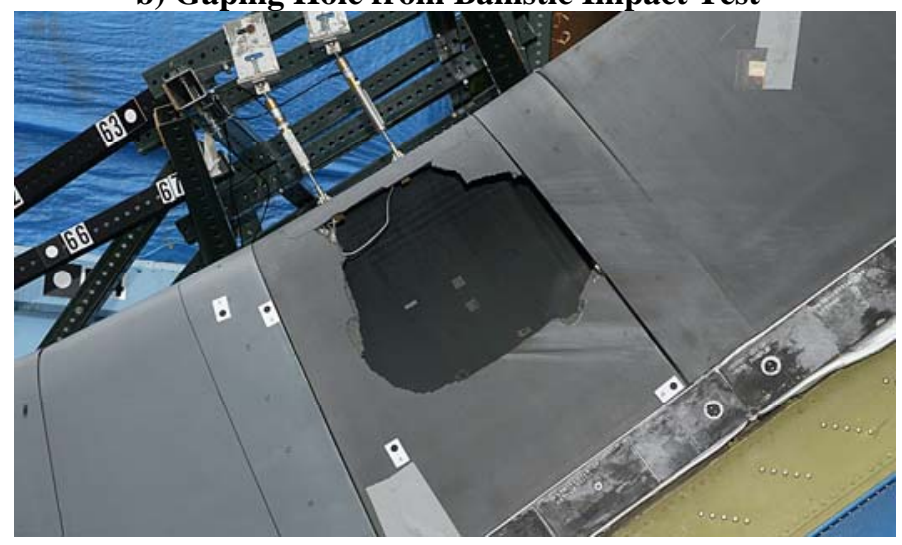

Figure 1. Foam Debris Hazard.

Since Shuttle flight STS-114, the primary goal of WLEIDS has been to detect ascent debris impacts to help the Mission Management Team (MMT) make critical safety decisions. Since flight STS-121, the system's role has been extended to monitor micrometeoroid and orbital debris (MM/OD) impacts. During each flight, the system uses accelerometers to detect dynamic response caused by impacts on the RCC panels. Other sensors such as acousticemission and fiber optic had also been considered (Ref. 9). Impact indications gathered from WLEIDS and the ground/vehicle camera surveillance systems would provide inputs to the on-orbit inspection of RCC. An early general inspection using the Laser Dynamic Range Imaging (LDRI) on the Orbiter Boom Sensor System (OBSS) is scheduled on Flight Day 2 to scan for ascent debris damage. The MMT then decides if a more detailed focus inspection is needed to determine if damage is severe enough to merit repair. Late inspection is performed to detect potential damages mainly due to MM/OD. All information regarding debris impacts is then used in an integrated assessment of structural integrity prior to Orbiter re-entry.

During early inspection for flight STS-132, the LDRI could not be properly positioned because its pan-tilt unit cable was snagged by a protruding sensor. This resulted in limited coverage and resolution that prevented clearing the RCC from ascent debris damage. While an additional extra-vehicular activity was planned to free the cable, the Orbiter Project Office (OPO) reviewed the limited early inspection results supplemented by other imagery surveys. On Flight Day 5, additional results from WLEIDS helped the OPO reach a consensus that the RCC was at a low risk of having sustained any unacceptable damage from expected ascent debris (foam and ice). The MMT subsequently proceeded with the mission while deferring the re-entry clearance to routine late inspection. 
The use of WLEIDS in making this critical decision came at a time when most of the analytical development milestones had been achieved, particularly through Probabilistic Risk Analysis (PRA) (Ref. 10). A computational PRA typically involves the use of complex physical "stress-strength" models to represent the associated failure criteria (Ref. 11). While these models are developed based on deterministic knowledge of a particular physical phenomenon, probabilistic methods are used to account for their uncertainty. In space launches, these models have been used to assess range safety involving risk of injury or loss of life in populated areas following a launch accident (Ref. 12-13), due to inert debris from launch vehicle, blast effects from solid or liquid propellant explosion (Ref. 14), and health effects from dispersion of toxic propellant plumes (Ref. 15). They have also been used in dealing with MM/OD risk (Ref. 16), Shuttle and ISS subsystem component criticality assessments (Ref. 17-19), and determination of Orbiter re-entry overflight hazards (Ref. 20-21). For WLEIDS, PRA is used to quantify the elevated risk as the conditional probability of damage, in the event that an impact is indicated by the system.

\section{Instrumentation}

The WLEIDS hardware system (Figure 2) was developed by Invocon (Ref. 22) and maintained by NASA (Ref. 23-24). During initial development, impact testing at Southwest Research Institute (SwRI) showed that the system is capable of detecting an RCC impact from foam similar in size and velocity to the Columbia incident. The hardware was later certified and flown aboard the STS-114 mission of the Orbiter Discovery. The on-board instrumentation consists of 132 accelerometers and 44 resistive temperature sensors mounted in the wing spars behind the RCC panels. Groups of three accelerometers and one temperature sensor are connected to one of the 44 battery-powered wireless data acquisition sensor units to record accelerations using a $20 \mathrm{kHz}$ sampling rate with a 6 $\mathrm{kHz}$ anti-aliasing filter. The sensor units are mounted at two separate locations or "farms" in each wing, with 14 units inside the aft wing cavity and 8 inside the forward wing glove (Figure 3). Grouping the units into farms instead of distributing them across the wings allowed ease of operation including battery replacement and post-flight data download through wheel well access panels. This also avoids damaging the sensitive wing struts due to battery hazard or loose instrumentation. The sensor units transmit the data to a wing relay unit via radio frequency (RF), then to a cabin relay unit via an RS-485 serial bus cable. The cabin relay unit transmits the data via RF to the laptop receiver unit, which then dumps the data to the laptop on board the flight deck. The data are finally downlinked to the ground via satellite KU-band for analysis.

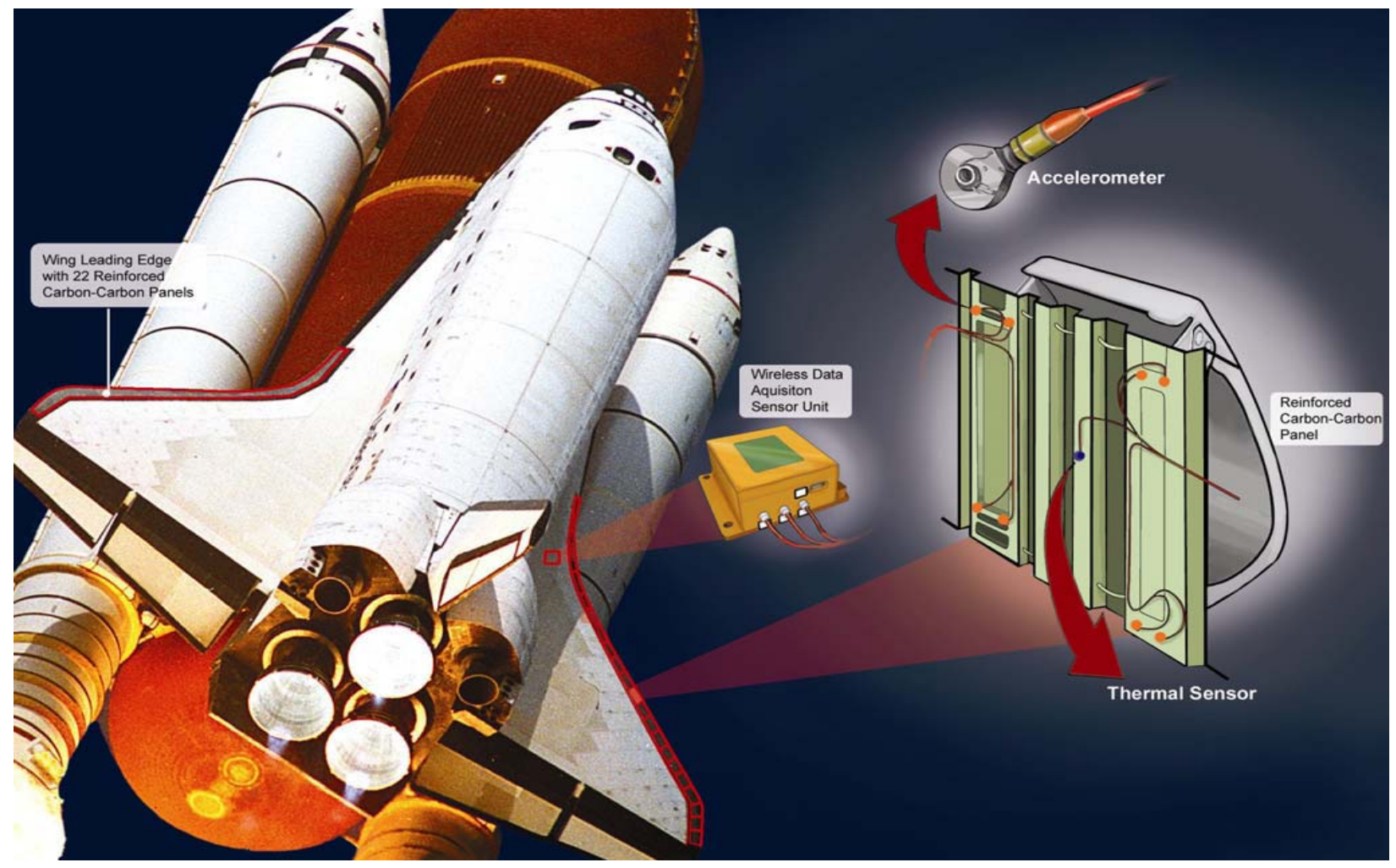

Figure 2. WLEIDS Hardware Overview. 


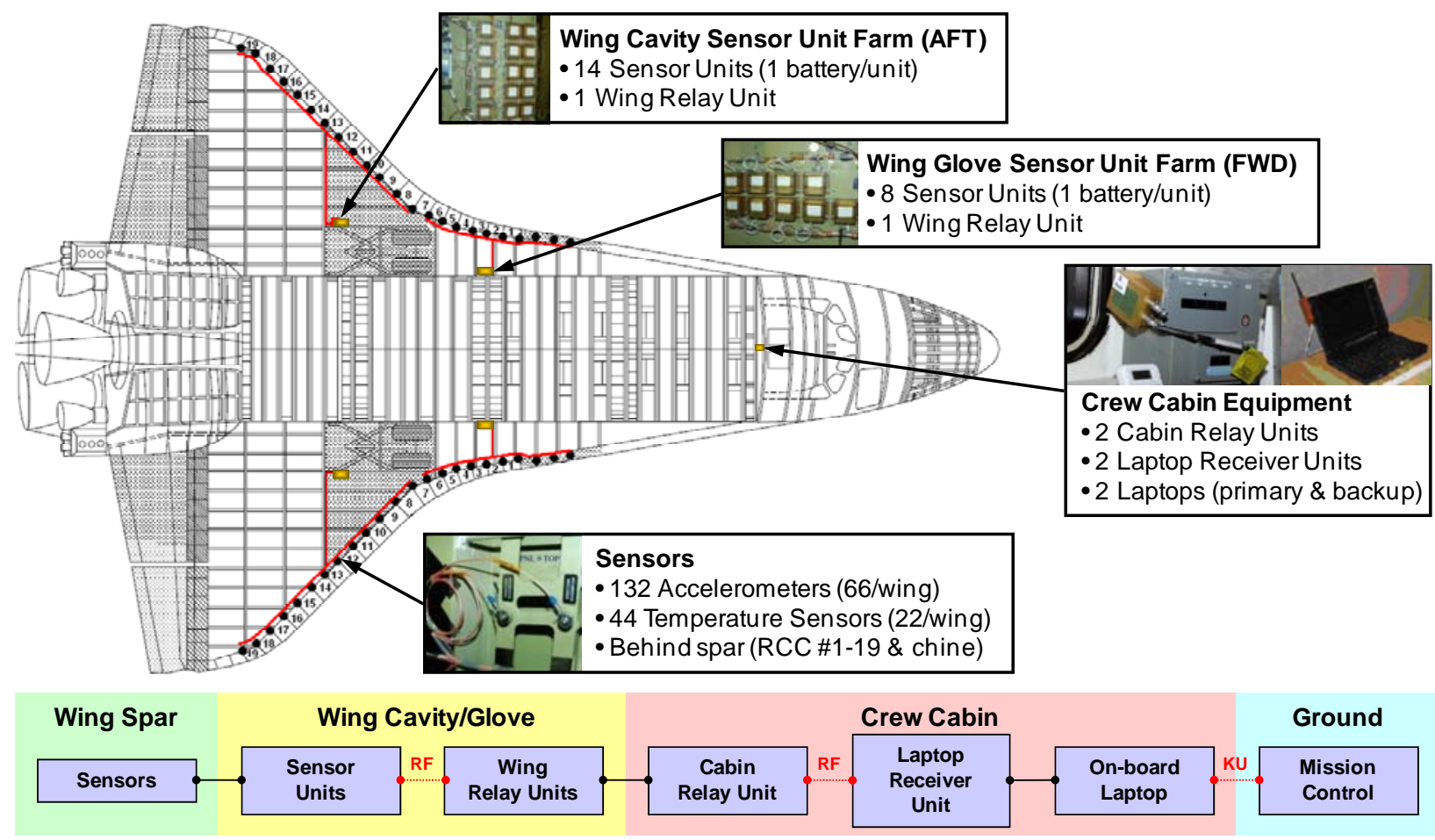

Figure 3. WLEIDS Instrumentation.

\section{Ascent Monitoring}

The exterior of the ET is covered with foam to insulate the tank filled with cryogenic liquid propellants from ascent aero-heating, and to prevent prelaunch icing that has high damage potential to the Orbiter when it sheds. The foam insulation was expected to stay on, yet foam shedding has been common since early flights. Although Orbiters have been damaged by ascent debris, the threat from foam shedding was not well understood until after ST-107. The Columbia tragedy prompted improvements to the ET foam design, spraying technique, and understanding of the integrated debris risk. The foam threat was mitigated by these improvements, but not eliminated. This is evident in post-Columbia flights, particularly the unexpectedly large foam debris spray during flight STS-127; hence the continued need for WLEIDS. Figure 4 shows the sensor configuration used in ascent monitoring, with sensors mounted across 22 RCC panels and the chine area of a wing. Each sensor unit is connected to three accelerometers typically distributed across two panels for fault tolerance. There are redundant accelerometers, particularly at RCC \#8-12 that are most critical for protecting the vehicle from re-entry aero-heating.

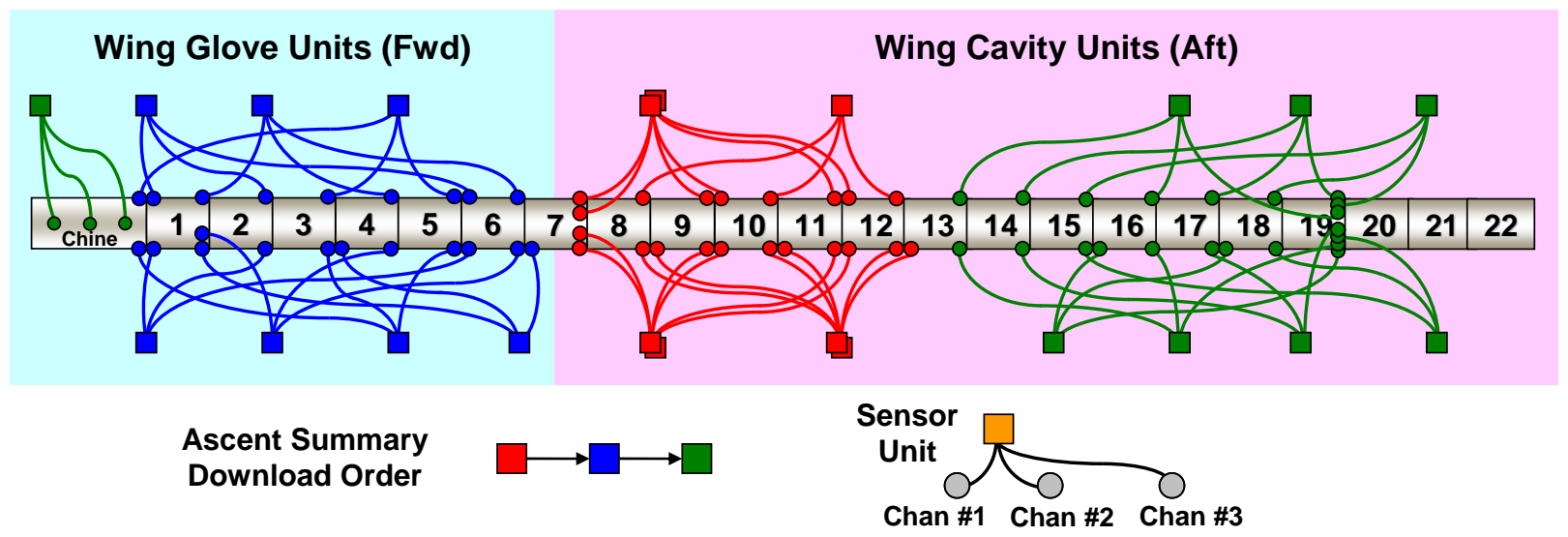

Figure 4. Ascent Monitoring Sensor Configuration. 
Before launch, the sensor units are programmed to take acceleration measurements in trigger mode. When triggered by liftoff vibrations, the units begin to store the data in internal memory for 10 minutes, going well past ET separation. The data take produces 12 million points for each of the 132 channels. Each sensor unit post-processes the $G$-time data into $G_{r m s}$ using 256-point $(0.0128 \mathrm{sec})$ windows with $50 \%$ overlap, and generates $312.5 \mathrm{~Hz}$ highpass filtered periodic summary files that select the highest $G_{r m s}$ point over each channel for every 1/2-second period. The sensor units return to idle mode after processing the data. Following orbit insertion, the crew sets up the onboard primary and backup laptops. Commands are sent to the sensor units to download the data to the laptops. As data files are written to the laptops, they are downlinked to the ground analysis team. Instead of the large volume of raw $G$-time data files, the $G_{r m s}$ summary files are downlinked with priority given to the most critical RCC panels (Figure 4). The summary greatly reduces the data while providing sufficient details to identify specific areas of interest where impacts are suspected. A command can then be uplinked to obtain a section of the processed data, or a limited number of $1 / 2$-second raw data files for further analysis. The two-step approach avoids the need for a large communication bandwidth to complete the analysis. After the Orbiter lands and is towed back to the processing facility, the full set of raw data files are downloaded by ground operations personnel for post-flight study.

During the ascent phase, the Shuttle undergoes a dynamic aero-acoustic environment marked by events such as Space Shuttle Main Engine (SSME) ignition, Solid Rocket Booster (SRB) ignition, Roll Maneuvers, Maximum Dynamic Pressure (Max Q) and SRB separation, and ET separation (Figure 5). Structural responses to dynamic loadings are recorded by WLEIDS. The challenge for the ground analysis team is to discern from all these dynamic responses whether a debris impact has occurred, and if so, determine when and where it occurred, and how severe it is. Figure 5 shows an example plot of summary data for the port wing. Among the major dynamic events shown, SRB and ET separations are distinctly seen because they are discrete and global. Chine sensors typically show higher response sensitivity (Figure 5). Certain RCC panel interfaces (e.g., 11/12, sometimes 6/7 and 16/17) may show a higher level of noise and repeated transients that are not attributed to real debris impacts. The summary files are screened to find areas of interest where potential impact events are suspected to have occurred. The screening can be slow and labor intensive. Experimentation using general purpose data mining tools (clustering, outlier method, decision tree) (Ref. 25-26) was conducted in flights STS-115 and 116. An expert systems approach was later employed to build an automatic detection tool by searching for data characteristics based on impact simulation and test experience. Further assessment demonstrated the tool's ability to produce a manageable list of points without missing any impact indications that an experienced analyst would have found. As the tool became a significant time saver while safeguarding against visual prevalence that the analysts might experience, the analysis procedure was revised to adopt a computer aided process that takes advantage of the use of automatic detection.

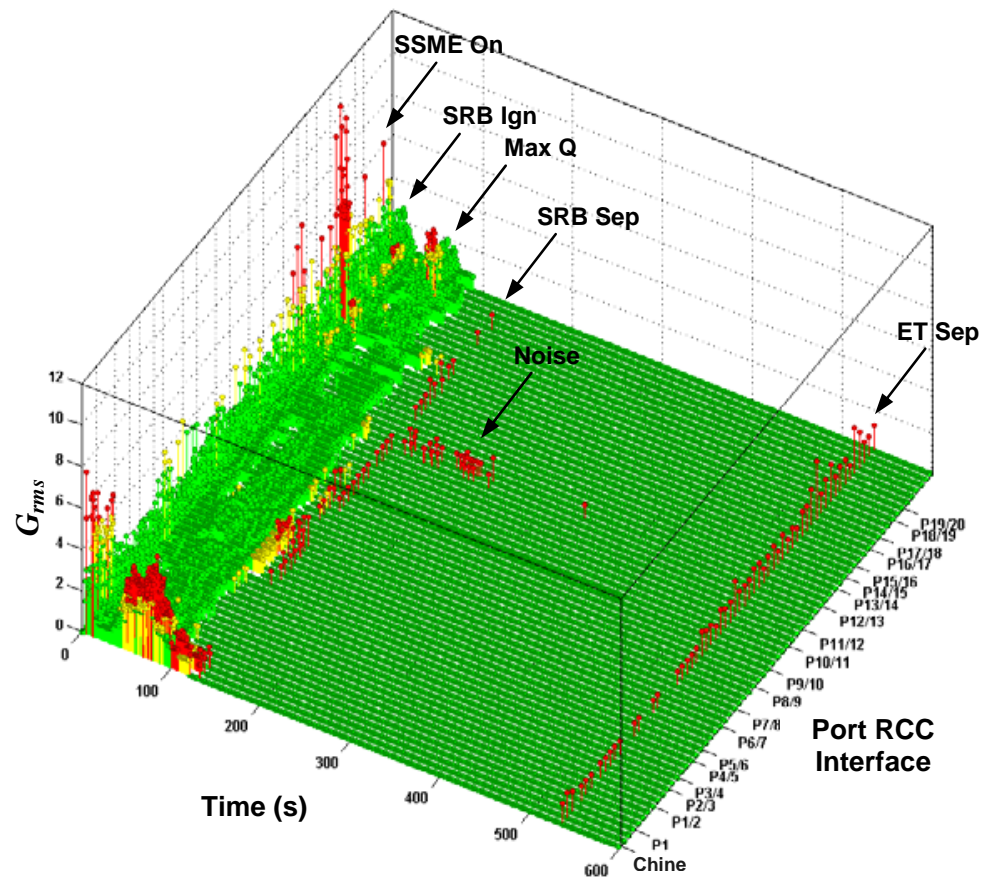

Figure 5. Ascent Processed Data Summary.

American Institute of Aeronautics and Astronautics 
Subsequent investigation following the summary analysis requires $1 / 2$-second raw $G$-time response data to be downlinked at the points-of-interest. The raw data analysis procedure was formalized by establishing a set of impact criteria. The first sign of impact that an analyst looks for is significant transient or sudden elevated response above noise in the $G$ - and $G_{r m s}$-time response plots (Figure 6a-b) over mission elapsed time. Due to the random vibration environment that the vehicles experience, the noise level changes over the ascent flight phase. The noise band (shaded yellow) is defined by the median absolute deviation (MAD) about the median over the $1 / 2$-second signal window, which provides a robust measure of signal variability with minimal influence from the transient. The shock response is expected to show a quick rise in amplitude followed by damped oscillation. The analyst checks to make sure that the transient is not due to an expected mission event (e.g., SRB and ET separations), which typically causes global dynamic response across both wings. Spectral analysis via Fourier transformation of the signal is used to find high frequency response typically excited by an impact (Ref. 27) (Figure 6c). Aero-acoustic and electrical transients often do not meet this criterion. Other analysis tools based on normal probability, wavelet transformation, crosscorrelation, multi-sensor signal demodulation, and spectral energy statistics were also developed. An initiative to improve the screening capability for on-orbit monitoring expanded the impact criteria by considering damping characteristics, multi-sensor corroborations, and nonlinear phenomena. The damping and multi-sensor criteria were also applied to ascent impact identification. An algorithm was developed to estimate the damping or logarithmic decay based on a fitted curve (Figure 6d). The damping criterion helps screen out much of the internal structural noise that has been known to exhibit a higher rate of signal decay than a real debris impact. Multi-sensor criterion exploits significant corroborating response from adjacent sensors to substantiate an impact indication. This criterion will be further discussed in the next section.

\section{a) G-time Response}

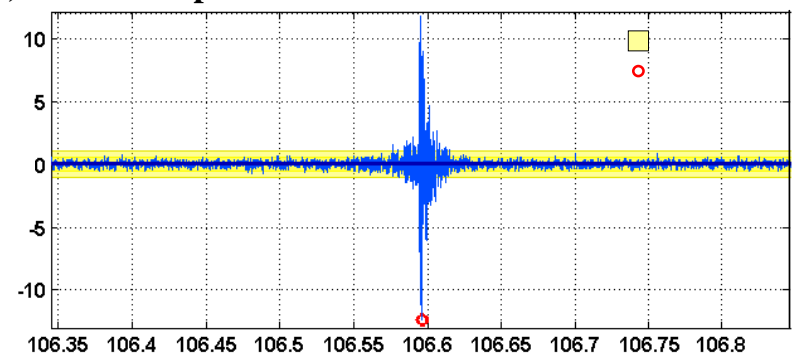

c) Power Spectral Density

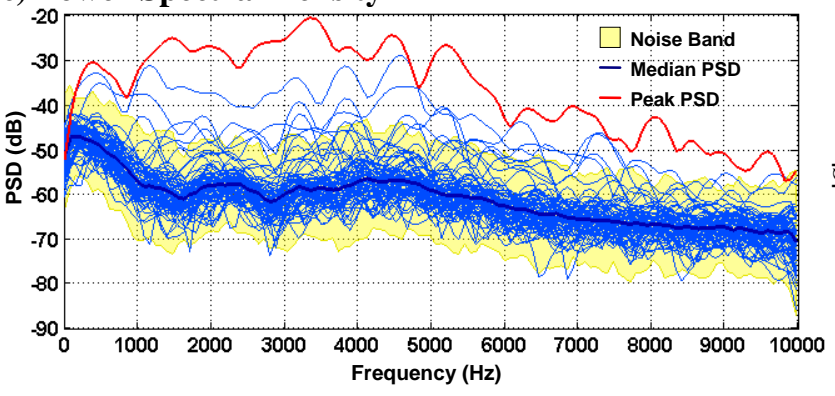

\section{b) $G_{r m s}$-time Response}

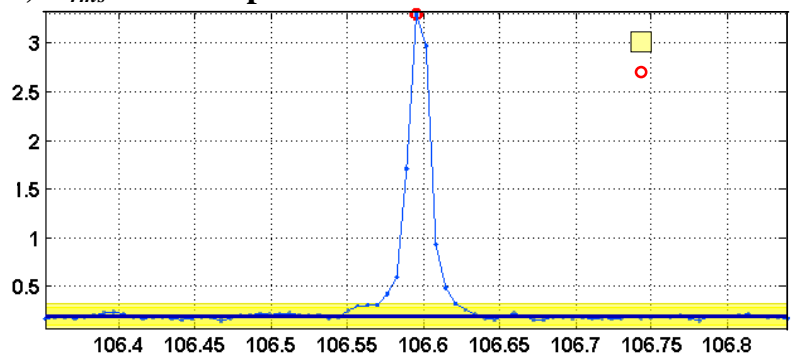

d) Damping

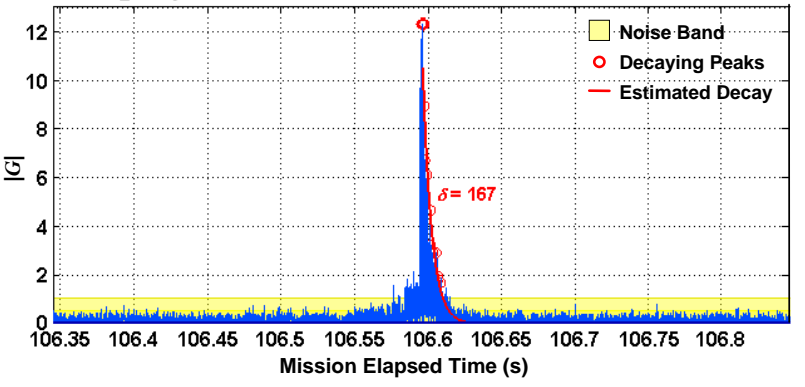

Figure 6. Example Analysis Plots.

In a typical Shuttle ascent flight, the system detects as many as 100 indications that are mostly associated with low energy, non-damaging, small foam (known as "popcorn") debris impacts. Popcorn foam releases occur as ET aero-heating causes an internal pressure build-up and burst of small pores in the foam insulation. Figure 7 shows a typical ET aero-heating curve superimposed on the temporal distribution of WLE IDS ascent debris impact indications averaged over flights STS-114 thru 120. A strong correlation between them can be clearly observed. However, while the aero-heating curve exhibits a clear "double-hump" characteristic, the second WLEIDS data "hump" is much less pronounced. This is thought to be due to significantly reduced atmospheric pressure and drag that resulted in much lower energy impacts. The correlation provided the first strong evidence of the system registering real impacts. The evidence helped establish high confidence in the system's sensitivity to detect more severe foam impacts, such as the one that critically damaged the Shuttle Columbia. 


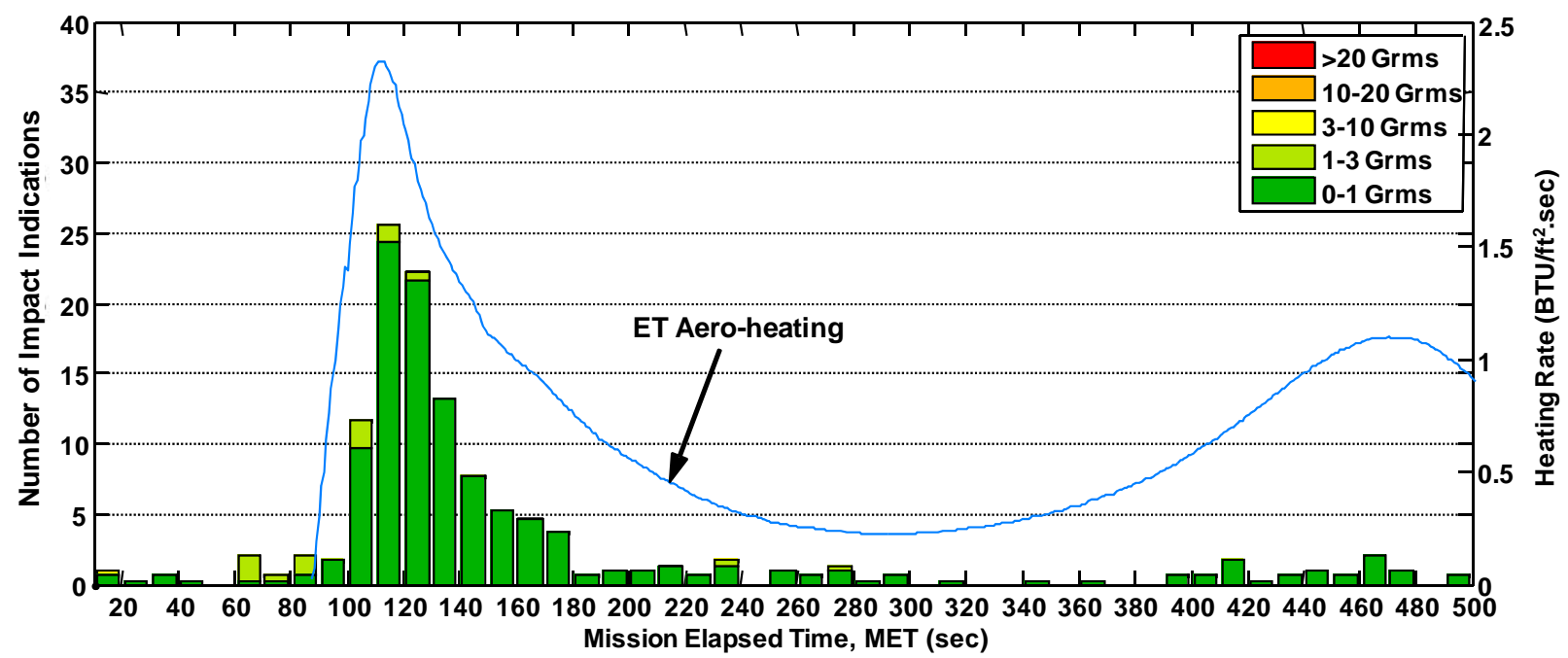

Figure 7. Correlation of Ascent Debris Impacts with ET Aero-heating.

While the large number of impact indications from each flight provided valuable insights to the ascent debris environment, they also posed an operational dilemma. The analysis team would not be able to find and report all of the impact indications within a practical time frame during the mission. Reporting all ascent debris impacts without inferring on their severity would not be very helpful either. It was realized that performing a severity assessment is key to a more robust decision process. Ascent analysis for a severity assessment was supported by an extensive testing and model development program. An important milestone was the development of a reporting threshold using the data acquired from SwRI ballistic impact tests (Figure 8), where debris samples (ET foam, ablator, ice) of various sizes and velocities were projected at full-scale wing leading edge test articles representing various designs and regions of the Orbiter wing structure. Using a test-based PRA approach, the Program selected a reporting threshold of $1.0 G_{r m s}$, a value below which there is high confidence that an impact would not be damaging. The application of reporting threshold to summary data analysis significantly reduced the report turnaround time by cutting down on the number of points-of-interest and $1 / 2$-second raw data downloads that need to be analyzed. Since flight STS-121, this greatly enhanced the operational feasibility and sustainability of the system by reducing the analysis time and personnel resources required for mission support.

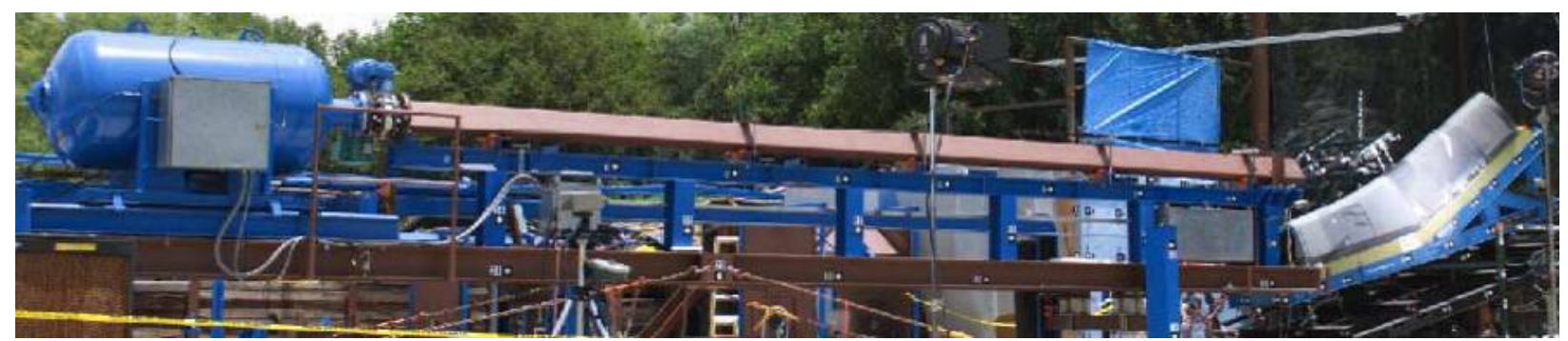

Figure 8. Ballistic Impact Test with a Full-scale Wing Leading Edge Test Article.

Following the development of a reporting threshold, model-based PRA of expected ascent debris (foam and ice) impacts was performed to establish the damaging threshold based on probability of damage. The analysis scope was limited to estimating the damage threshold and probability without addressing the damage extent or the overall Orbiter re-entry risk. The PRA effort involved vehicle thumper testing at Kennedy Space Center (KSC), NASTRAN modeling and simulation, probabilistic LS-DYNA damage threshold analysis, sensitivity analysis, and statistical damage analysis of model runs. Models developed in LS-DYNA (Figure 9a) (Ref. 28) and NASTRAN (Figure 9b) were correlated to SwRI ballistic impact tests. The NASTRAN high-fidelity vehicle wing model (complete with spar, fittings, and RCC panels) was later validated by a series of low energy non-destructive vehicle impact tests performed using a thumper and arm assembly. As part of the pre-test planning, a test article experiment was conducted to help modify the thumper design for better load consistency. The test article and vehicle models were used to ensure safe thumping. The calibrated thumper was then used to carefully tap the RCCs of OV-105 (Figure 9c) (Ref. 29). A total of five locations were thumped on fourteen panels (RCC \#5-18) for each wing. Nondestructive evaluation (NDE) was conducted to verify that the thumper test had not caused any damage to the RCCs 
(Ref. 30). Following the test, NASTRAN model runs were generated with measured inputs from thumper test for model validation and uncertainty assessment. The modeling uncertainty was assessed by statistically averaging over all model errors, although more advanced techniques had been considered for predictive accuracy assessment (Ref. 31-33). Due to the significant modeling uncertainty, and without regularization of model update (Ref. 34), the model was more suitable for probabilistic as opposed to deterministic analysis.

a) LS-DYNA Simulation

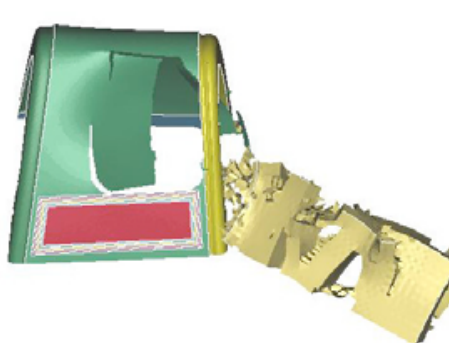

b) NASTRAN Model

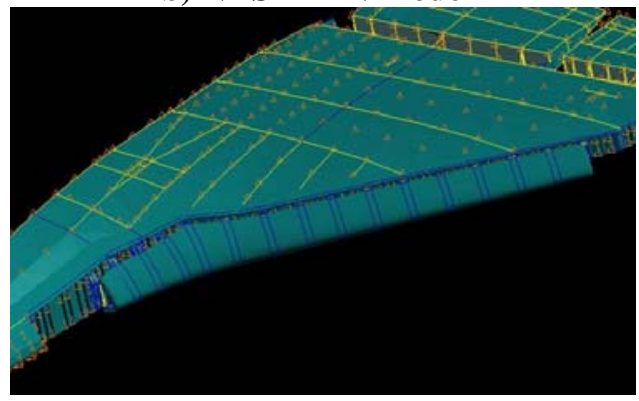

c) Vehicle Thumper Test

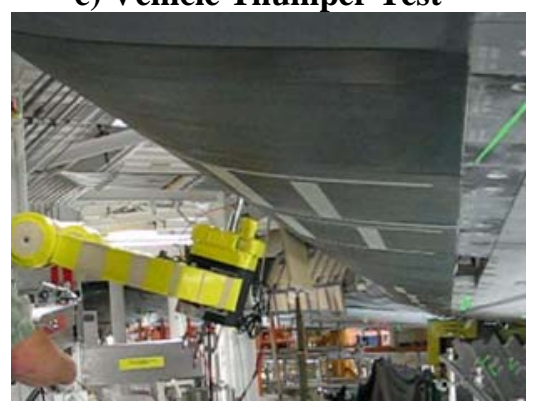

Figure 1. PRA Modeling and Testing.

In computational PRAs, probabilistic "stress-strength" formulation based on a phenomenological model is typically used to predict the reliability of structural elements by estimating the probability distribution of mechanical "stress" applied to a structural component and of the "strength" of its constituting material (Ref. 11). The probability of failure of the component is then calculated as the probability that the applied stress may exceed the inherent strength. A similar formulation was used in the ascent severity assessment. About 300 model runs were generated using the inputs of LS-DYNA threshold cases to calibrate the damage evaluation. The analysis of these cases for each debris type (foam, ice) over normally distributed material variations produced the statistical distribution of maximum principal stress (Figure 10a). Sensitivity analysis was used to determine the model run matrix, where a total of 34 runs per debris type on one panel (RCC \#9) were generated at selected parameter variations. As for risk analysis, 1050 model runs were generated for each debris type for RCC \#9-17, while 450 runs were generated for the smaller RCC \#5-7, and 700 runs for RCC \#8 due to consideration of a large debris contact footprint relative to the panel size. For each debris type, the debris weight, impact location, angle, and velocity were varied in the simulations. This allowed the PRA to take into account the varying response sensitivity (due to mass and geometry) across the wing. For most panels, there were nine impact locations ( $3 \times 3$ grid) on both lower and upper surfaces, and three locations along the apex (Figure 10b). The midpoint of each surface corresponds to the impact location of the LS-DYNA threshold cases. The narrower panels (RCC \#5-7) had only two columns of impact grid points instead of three. Debris weight was varied between 0.01-0.1 lb for foam and 0.005$0.06 \mathrm{lb}$ for ice. Impact angles were varied with pitch ranging between $0-10^{\circ}$, while azimuth was kept at $5^{\circ}$. Debris impact velocity was varied based on the LS-DYNA threshold runs for each debris weight, with values ranging from 250 to $2200 \mathrm{ft} / \mathrm{sec}$ for foam, and 100 to $1700 \mathrm{ft} / \mathrm{sec}$ for ice.

a) Probabilistic Damage Evaluation

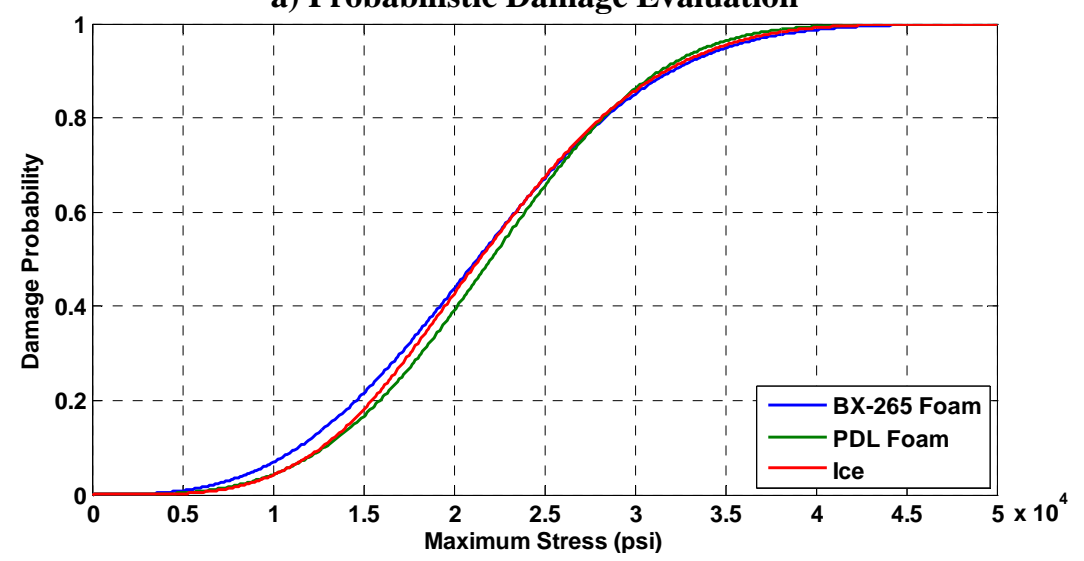

b) Model Impact Locations

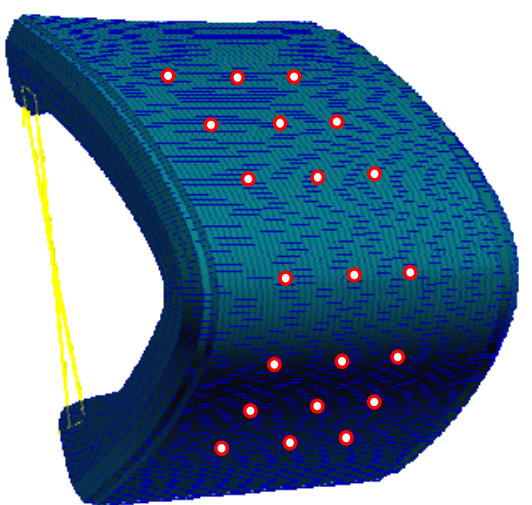

Figure 2. Probabilistic Impact Analysis. 
The analysis took into account the varying response sensitivity across the wing (due to RCC panel mass, geometry, and boundary conditions), and impact uncertainty (location, angle, velocity, debris type). Maximum principal stress and dynamic response were calculated from the model with response correlated with the thumper test. The response data went through flight-consistent post-processing to obtain the maximum $G_{r m s}$. Maximum principal stress was used to estimate the damage probability. Relating maximum $G_{r m s}$ to damage probability allowed the damage risk to be quantified based on accelerometer measurements acquired from an impact indication. Figure 11 shows the damage probability contours over panel number and maximum response, with the lowest maximum $G_{r m s}$ conservatively selected over debris types and impact surfaces (lower, apex, upper). These curves show that the higher the response, the higher the damage probability for the same panel (as expected). They also reflect the different response sensitivity across the panels. The larger panels (RCC \#8-9) tend to have lower sensitivity, hence lower response for the same damage risk. During flight, when the system registers an ascent impact indication, the impact magnitude and impacted RCC panel number would be used to infer the associated damage risk. The ascent impact indications would then be ranked in the order of importance (e.g., for focused inspection) based on their damage risk. The analysis is limited to providing risk acceptance rationale only when the damage probability falls under 1/100. An impact similar to one brought down the Shuttle Columbia could have produced a response over $40 G_{r m s}$ for RCC \#8, with a damage risk well above $1 / 100$. The analysis also found that the previously selected reporting threshold of $1.0 G_{r m s}$ did not exceed a damage probability of 1/1000 for any panels, thus verifying that using this value as the lowest threshold of concern is appropriate for mission operations.

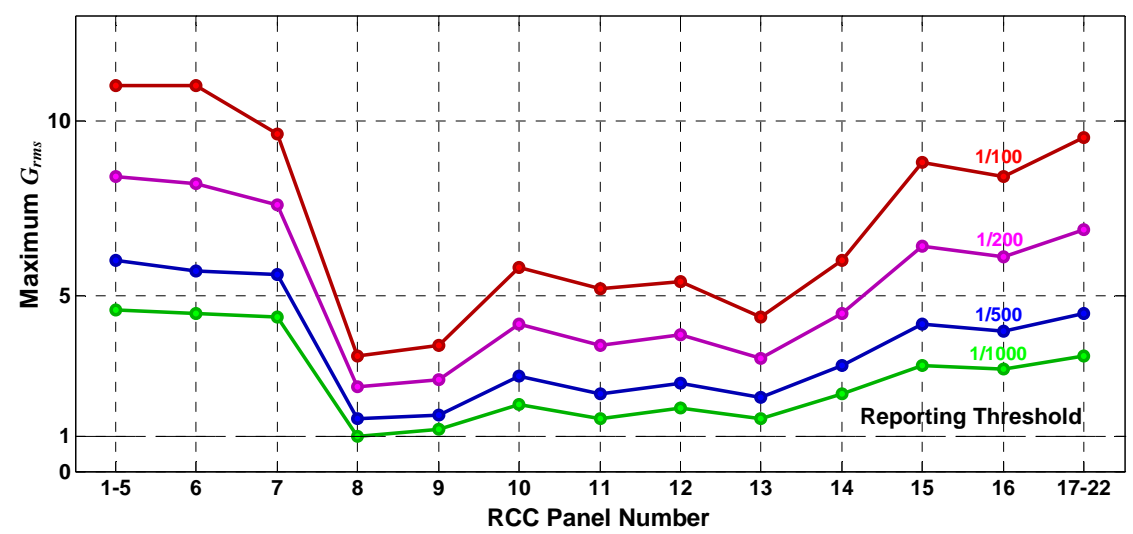

Figure 3. Damage Risk from Ascent Debris Impact Indication.

As a mission support example, the ascent analysis was completed within twelve hours of launch during flight STS-132. Only one probable impact indication from starboard RCC \#6 was reported, with the risk of RCC damage from expected ascent debris (foam and ice) estimated at no more than $1 / 1000^{\dagger}$. As previously mentioned, an OBSS positioning problem prompted the OPO to assess the RCC damage risk before clearing the vehicle from ascent damage and proceeding with the preplanned mission activities. As part of the decision process, the concern of damaging impacts being potentially masked by aero-acoustic noise during the period of high dynamic pressure was raised. Damage risk was conservatively assessed by treating the Max Q response (highest noise after take-off) as an impact response. The results showed that most panels had an acceptable damage risk below $1 / 1000$, and for those few with higher damage risk below $1 / 500$, the concern was sufficiently alleviated by supplementary imagery and inspections. The PRA results from WLEIDS played a key role in making a critical flight safety decision.

\section{On-orbit Monitoring}

Micrometeoroids are interplanetary particles broken off from larger debris that usually date back to the formation of the solar system. The material may range from stony silicate minerals to metallic (iron, nickel). Man-made orbital debris (e.g., fragments from satellites and rockets) also pose serious risk of collision with space structures. Although undesirable, MM/OD impacts are common during Shuttle missions, evident by small craters on the RCCs, thermal tiles, and radiator (Ref. 35). During flight STS-121, the system demonstrated its capability in monitoring for MM/OD impacts. Data gathered from flight STS-114 were used to set the triggering parameters in the firmware. The capability has since been put in use to guide the late inspection (Ref. 36).

\footnotetext{
$\dagger$ The indication is not necessarily the most severe impact (i.e., the highest damage probability) from the flight, as other more severe indications may not have been reported because their impact magnitudes were below the reporting threshold of $1.0 G_{r m s}$.
} 
During on-orbit monitoring, the sensor units are divided into two groups (Figure 12) per wing that cycle through idle and trigger modes for the remaining flight. Limited battery capacity under the extreme thermal environment does not permit continuous monitoring. Hardwiring to the vehicle power source had been considered but not implemented due to cost and noise concerns. Sensor units put in trigger mode consume battery power at a much higher rate than in idle mode. As the Orbiter changes its attitude over time, the MM/OD risk profile passes through elevated periods, mainly during early and late inspections, as well as docking and undocking with the ISS. An optimal on-orbit monitoring plan activates the sensors into trigger mode during these elevated risk periods, with priority given to warmer temperatures for better use of battery capacity, and earlier flight time when there are more options for further inspection or repair. The number of starts and stops is also minimized to simplify the operations and limit high transient current draws. The on-orbit operation leaves a substantial amount of nominal risk periods unmonitored. Thus the system cannot be used to completely mitigate MM/OD risk to the RCC.

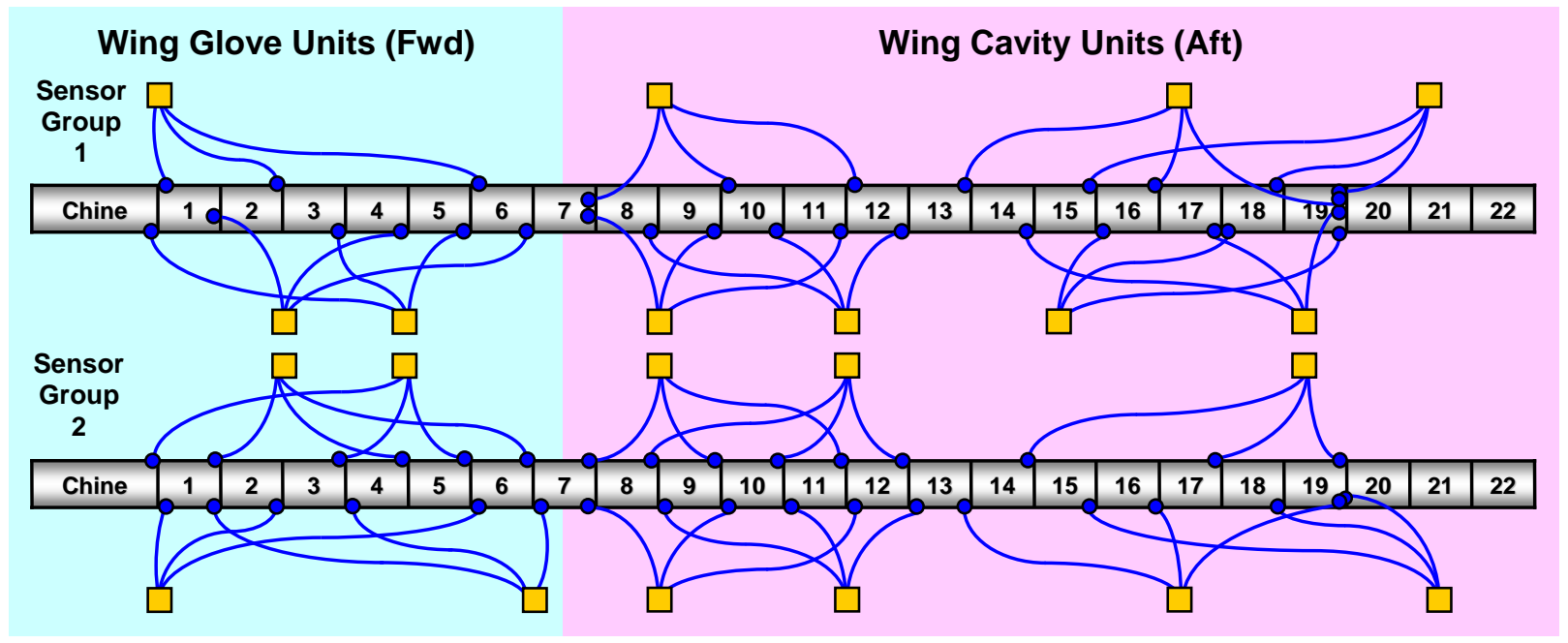

Figure 4. On-orbit Monitoring Sensor Configurations.

The criteria used for MM/OD impact identification include those for ascent. However for on-orbit monitoring, evaluating these criteria based on one sensor alone can lead to false positives; numerous triggers that passed these criteria were later cleared by post-landing ground inspection, as the expected damage could not be substantiated by the inspection results. An initiative prior to flight STS-126 improved the on-orbit monitoring capability by screening out the previous triggers as spurious (structural noise) or anomalous (not the high risk impacts as tested or modeled). The effort led to the development of a multi-sensor discriminator that takes the corroborating response from other sensors adjacent to the peak response into account. Response ratios $\left(r_{\text {diag }}, r_{\text {horz }}\right)$ calculated from diagonal and horizontal corroborations (Figure 13) are evaluated and checked against their thresholds established from model and test. There can be two, three, or four sensors (excluding redundancy) monitoring an indicated panel. With two sensors, either diagonal or horizontal corroboration is available, but not both. With three, diagonal, horizontal, or both may be available depending on the $G_{\max }$ location. With four, both diagonal and horizontal are available. Multisensor criterion supports a probabilistic evaluation. When only one of the two corroborations is available, each ratio is compared to a univariate distribution of flight and model data. When both are available, a bivariate distribution is used. The latter mostly benefits analysis of the critical panels (RCC \#8-12) due to higher sensor density (Figure 12). The impact probability is estimated as

$$
P_{I}=P_{M} /\left(P_{M}+P_{F}\right),
$$

where $P_{M}$ is the probability of corroboration ratio being above those from model, i.e. true impacts substantiated by significant corroborations, and $P_{F}$ is the probability of corroboration ratio being below those from flight, i.e. spurious impacts substantiated by weak corroborations.

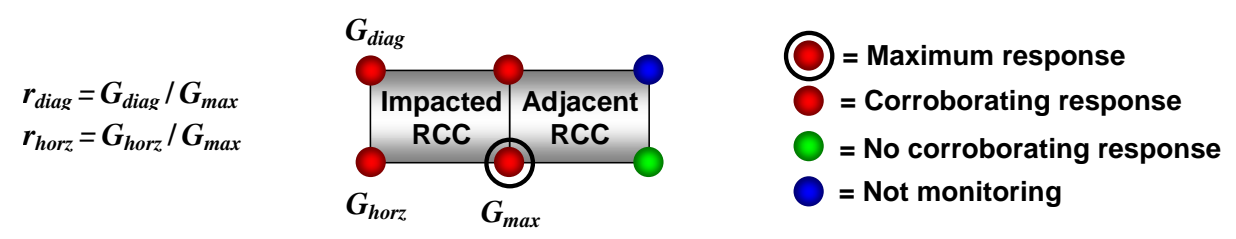

Figure 5. Multi-sensor Corroboration Ratios.

10

American Institute of Aeronautics and Astronautics 
Given a probable impact indication from WLEIDS, it is essential to address the severity of an MM/OD impact event that puts the Orbiter in an elevated risk situation. The impact severity is expressed in terms of expected damage size (with uncertainty) and damage risk (probability of damage size exceeding some critical value). The damage allowable (critical damage size) depends on re-entry aero-heating, with values ranging from 0.08 to 1.0 inch over different RCC panels and surfaces (typically lowest at the apex and highest on the top surface). The inference of severity from response magnitude is quite different from that of ascent debris due to the different damage mechanism associated with hypervelocity impact phenomenon that excites higher frequency response (above 4 $\mathrm{kHz}$ ). To assess the severity, the joint probability of critical damage is expressed as

$$
P_{C}=P_{C / I} P_{I},
$$

where $P_{C / I}$ is the conditional probability of critical damage given an impact, and $P_{I}$ is the probability of impact (Ref. 16). The value of $P_{I}$ is estimated from multi-sensor criterion, while $P_{C / I}$ is estimated based on test and model experience. Hypervelocity impact tests (Figure 14a) were conducted at NASA White Sands Test Facility (WSTF) to investigate the effect of an MM/OD impact. A total of 20 shots were fired using Al 2017-T4 spherical projectiles to simulate micrometeoroids. Figure 14b shows the correlation between response and damage extent.

a) Hypervelocity Test Setup

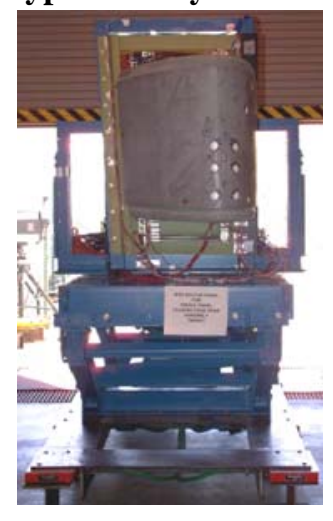

b) Damage Extent from Test

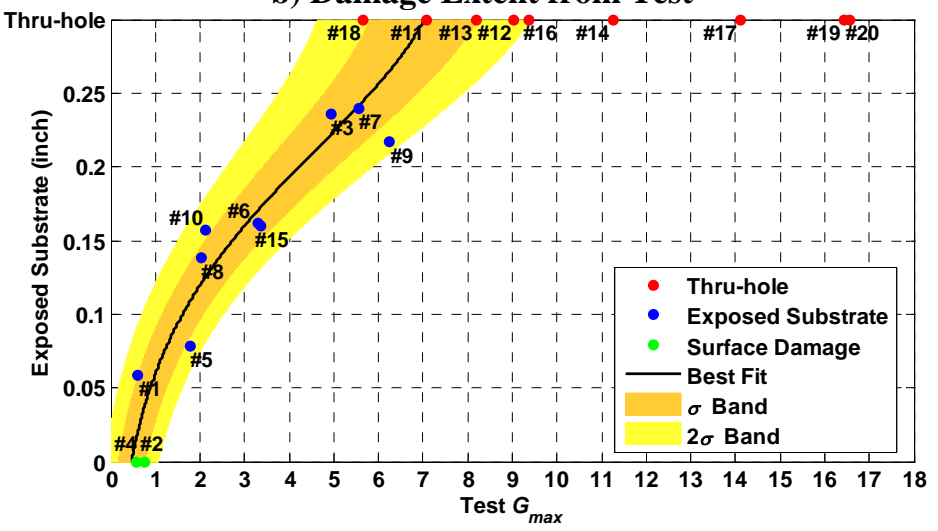

Figure 6. MM/OD Impact Test.

Test experience is drawn upon to estimate damage for a probable MM/OD impact indication. However, flight response has much lower sensitivity (about three times) than test and hence must be scaled. Several scaling factors derived from test data and model simulations are involved, and there is uncertainty associated with each of them. Due to reduced on-orbit sensor density, the number of active sensors around an indicated panel is different from test. While the test has sensors on all four corners around the impacted panel, flight typically has only three or two. This difference is compensated by a sensor configuration scaling factor, $\lambda_{\text {sen }}$, which was obtained using test cases (RCC \#16) and model simulations (multiple panels). A panel-to-panel scaling factor, $\lambda_{\text {pan }}$, is needed because an indicated panel is not necessarily the test panel (RCC \#16). The factor is calculated by comparing $G_{\max }$ from RCC \#5-17 impact simulations to those of RCC \#16. Due to the limited number of panels modeled, RCC \#5 or \#17 were used for panels further inboard or outboard. Another scaling factor, $\lambda_{t s t}$, is used to compensate for the higher test article response relative to vehicle, as test spar edge vibrates more freely than full vehicle spar. The test article scaling factor is calculated by comparing RCC \#16 simulations from the test article to the wing model. The cases were selected from 11 non-thru-hole tests with four sensors per test, totaling 44 responses. The hardware measurement scaling factor $\lambda_{\text {mea }}$ was obtained by comparing the original and reprocessed test responses. To be consistent with flight hardware, the original test data were resampled from $51.2 \mathrm{kHz}$ to $20 \mathrm{kHz}$ with anti-aliasing at $6 \mathrm{kHz}$. The damage- $G_{\max }$ correlation (Figure 14) was modeled using an inverse Weibull function. The distribution of correlation factor $\lambda_{\text {dam }}$ was obtained from test to account for substrate damage uncertainty. The distribution of $\lambda_{\text {sen }}, \lambda_{\text {pan }}$ and $\lambda_{\text {tst }}$ were modeled as a 3-parameter Weibull, while $\lambda_{\text {mea }}$ was modeled as a bimodal Weibull, and $\lambda_{\text {dam }}$ as Gaussian. To account for the uncertainty of these factors, statistical sampling (Ref. 37) based on these modeled distributions was used when performing the Monte Carlo analysis of damage size. The different damage estimates allowed us to define the conditional critical damage probability as

$$
P_{C / I}=P\left(d>d^{*}\right),
$$

where $d$ is the damage size estimated from scaled $G_{\max }$, and $d^{*}$ is the critical damage size or exposed RCC substrate for the most critical re-entry aero-heating zone on a panel. Figure 15 shows the $P_{C / I}$ curves over flight response. In general, higher response, less sensitive panels, and fewer active sensors contribute to higher damage probability. 

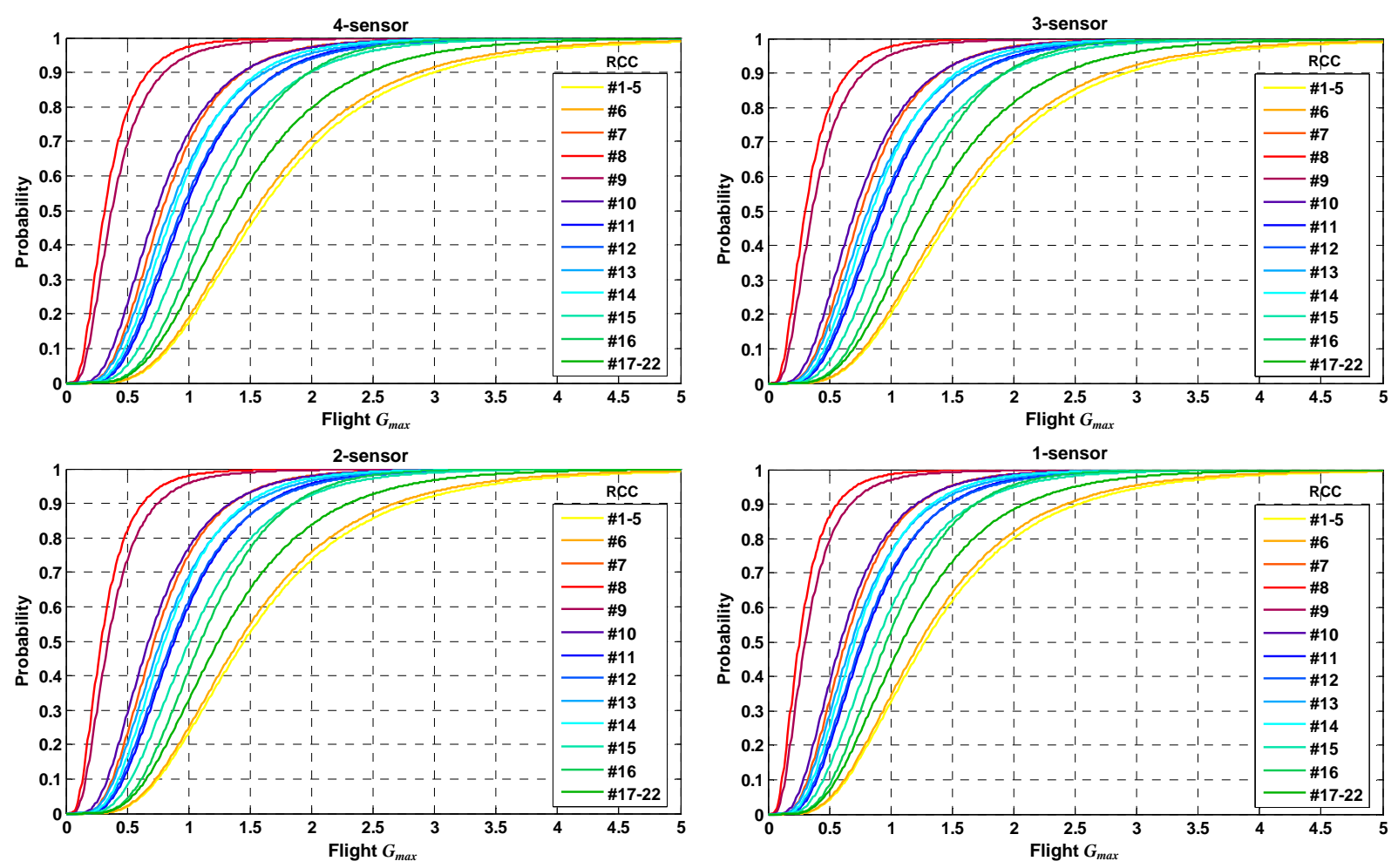

Figure 7. Critical MM/OD Damage Probability.

As an example MM/OD impact severity assessment, an on-orbit trigger from flight STS-125 indicated starboard RCC \#11 with a response magnitude of $0.47 G_{\max }$ (Figure 16a). The indication was corroborated by two other sensors outboard diagonal and horizontal from the maximum response, with corroboration ratios calculated as $r_{\text {diag }}=$ $0.26 / 0.47=0.55$ and $r_{\text {horz }}=0.46 / 0.47$. Both ratios exceeded their minimum thresholds for passing the multi-sensor criterion. The critical damage size $\left(d^{*}\right)$ for RCC \#11 is 0.16 inch. Figure $16 \mathrm{~b}$ shows the corresponding probability distribution of damage size, where the probability of exceeding the critical value was estimated as

$$
P_{C / I}=P\left(d>0.16^{\prime \prime}\right)=8 \% \approx 1 \text { in } 12 \text {. }
$$

It is possible to estimate the probability of thru-hole and onset damage as shown in the plot. However, the critical damage probability remains most relevant to an inspection decision because it is consistent with the damage criteria used for Orbiter re-entry.

a) Response Corroboration

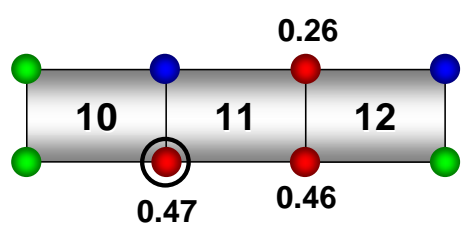

\footnotetext{
= Maximum response = Corroborating response $=$ No corroborating response $=$ Not monitoring
}

b) Damage Risk

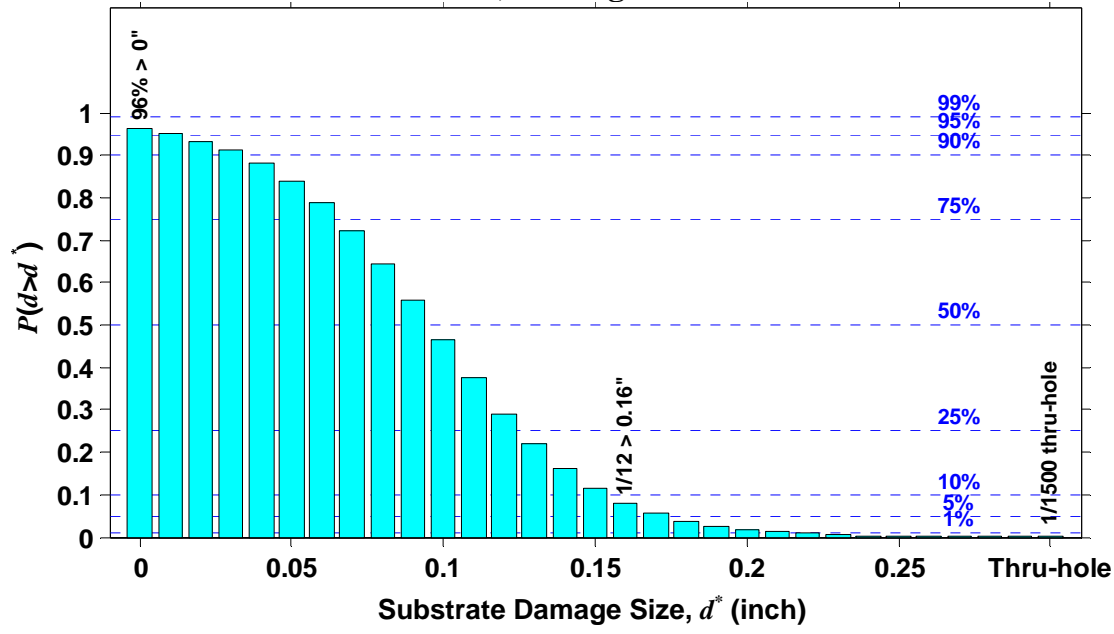

Figure 8. Example MM/OD Impact Case.

American Institute of Aeronautics and Astronautics 


\section{Conclusions and Future Development}

The debris hazard environment experienced by the Orbiter wing leading edge presented a challenging risk management problem. The problem was reconditioned by the development of WLEIDS such that the pertinent flight risk has become more manageable through hazard monitoring. The wireless instrumentation overcame many difficulties associated with incorporating the system into a completed structure, and provided a practical and cost effective platform on which an integrated impact sensing, signal processing, and analysis operation could be implemented. Due to strong development and continuous improvement efforts, WLEIDS has evolved into a fully operational structural health monitoring system that is now an integral part of critical decision making for Orbiter reentry safety. While the main purpose of WLEIDS has been to monitor ascent debris impacts, future launch vehicles will likely have an in-line design that will not expose the spacecraft to the same ascent vulnerability as the Shuttle. Therefore, the use of such monitoring systems for future manned space missions would instead focus on MM/OD impact detection. The main challenge is dealing with hypervelocity impact of medium size particles that are not easily tracked and yet large enough to cause serious damage (Ref. 38). The technology developed for WLEIDS, including its wireless instrumentation, interface firmware, and various impact analysis tools, will benefit future structural health monitoring for safer human transportation, exploration, and habitation of space. In particular, the advanced MM/OD impact criteria, as well as the probabilistic risk analysis approach developed for this system will contribute to a more reliable and robust impact detection and severity assessment. Meanwhile, new developments in sensor technology (Ref. 39-41) and energy harvesting techniques (Ref. 42) promise to revolutionize the future design of structural health monitoring systems.

\section{Acknowledgements}

The analysis work performed by Boeing is funded by the NASA Orbiter Project through United Space Alliance (USA). The authors would like to thank the WLEIDS team members from NASA, USA, Boeing, Lockheed Martin, ESCG, and Invocon, who have contributed tremendously to the development, operation, and maturation of the system over the years. In particular, we thank George Studor for the inception of the structural health monitoring system, Mike Dunham and Kelly Carney for their helpful advice and guidance, Ed Tong and Jerry Bohr for leading the modeling and vehicle thumper test efforts, Eli Rayos, Chip McCann, Max Maynard, Jennifer Hodge, and Jennifer Dean for mission planning and operations, and Eugene Wong, Nestor Dub, and Abel Noah for contributing to the analysis work. The authors also appreciate the inputs provided by various review panels, including the Structures, Loads \& Dynamics (SLD), Leading Edge Subsystem (LESS), Micro-wireless Instrumentation (MWIS), Safety \& Mission Assurance (S\&MA), and Debris Integration Group (DIG).

\section{References}

${ }^{1}$ Doebling, S. W., Farrar, C. R., and Prime, M. B., "A Summary Review of Vibration-based Damage Identification Methods," The Shock and Vibration Digest, Vol. 30, No. 2, pp. 91-105, 1998.

${ }^{2}$ Kaouk, M. and Zimmerman, D. C., "Structural Damage Assessment Using a Generalized Minimum Rank Perturbation Theory," AIAA Journal, 32 (4), pp. 836-842, 1992.

${ }^{3}$ Zimmerman, D. C., Smith, S. W., Kim, H.-M., Bartkowicz, T., “An Experimental Study of Structural Damage Detection Using Incomplete Measurements," ASME Journal of Vibration and Acoustics, 118 (4), pp. 543-550, 1996.

${ }^{4}$ Yap, K. C. and Zimmerman, D. C., "Damage Detection of Gyroscopic Systems Using an Asymmetric Minimum Rank Perturbation Theory," SPIE Series, Vol. 3727, 1999.

${ }^{5}$ Yap, K. C. and Zimmerman, D. C., "A Comparison of Modal Data Matching and Dynamic Residual Optimization in Structural Damage Detection," International Journal of COMADEM, Vol. 5, No. 4, p. 5, 2002.

${ }^{6}$ Fitzpatrick, K., Grygier, M., and Bartkowicz, T. "ISS Stage 12A Post-flight Modal Analysis, Model Validation, and Correlation," The 26th International Modal Analysis Conf. (IMAC), Orlando, FL, 2009.

7 Yap, K. C. and Hodge, J. C., "WLEIDS - An Operational Wireless Structural Health Monitoring System", JANNAF 4th Space Vehicle \& Propulsion Systems Wireless Sensors Workshop, Orlando, FL, 2010.

${ }^{8}$ Kosters, E. and van Els, T. K., "Structural Health Monitoring and Impact Detection for Primary Aircraft Structures," Proceedings of the SPIE, Vol. 7677, 2010.

${ }^{9}$ Prosser, W. H., Allison, S. G., Woodard, S. E., Wincheski, R. A., Cooper, E. G., Price, D. C., Hedley, M., Prokopenko, M., Scott, D. A., Tessler, A., and Spangler, J. L., "Structural Health Management for Future Aerospace Vehicles," The 2nd Australasian Workshop on Structural Health Monitoring, Melbourne, Australia, 2004.

${ }^{10}$ Keller, W. and Modarres, M., "A Historical Overview of Probabilistic Risk Assessment Development," Reliability Engineering and System Safety, Vol. 89, pp. 271-285, 2005.

${ }^{11}$ Stamatelatos, M. G., "Physical and Phenomenological Models," Probabilistic Risk Assessment Procedures Guide, Sec.14, NASA Office of Safety and Mission Assurance (OSMA), 2002. 
${ }^{12}$ Baeker, J. B., Collins, J. D., and Haber, J. M., “Launch Risk Analysis,” Journal of Spacecraft and Rockets, Vol. 14, No. 12, pp. 733-738, 1977.

${ }^{13}$ Collins, J. D., "Risk Analysis Methodologies Developed for the U.S. Department of Defense," Reliability Engineering and System Safety, Vol. 20, pp. 87-115, 1988.

${ }^{14}$ Wilde, P. D. et al., "Off-Base Blast Propagation Risk Analysis for Titan IV Launches," JANNAF Joint Propulsion Conf., Sunnyvale, CA, 1997.

${ }^{15}$ Philipson, L. L., Hudson, J. M., and See, A. M., "Exposure-response Functions in Air Force Toxic Risk Modeling," Toxicology - Risk Assessment Issues for Sensitive Human Population, Vol. 111, Issues 1-3, pp. 239-249, 1996.

${ }^{16}$ Kessler D. J. et al., "A Computer-Based Orbital Debris Environment Model for Spacecraft Design and Observations in Low-Earth Orbit," NASA JSC Technical Memorandum 104825, 1996.

${ }^{17}$ Paté-Cornell, E. and Dillon, R., "Probabilistic Risk Analysis for the NASA Space Shuttle: A Brief History and Current Work," Reliability Engineering \& System Safety, Vol. 74, Issue 3, pp. 345-352, 2001.

18 "NASA's Implementation Plan for International Space Station Continuing Flight," The International Space Station Program's Response to the Columbia Accident Investigation Board's Report, 2003.

${ }^{19}$ Stamatelatos, M. G., "New Thrust for Probabilistic Risk Assessment (PRA) at NASA," Risk Analysis for Aerospace Systems, Arlington, VA, 2002.

${ }^{20}$ Lin, M., Larson, E., and Collins, J., "Determination of Debris Risk to the Public due to the Columbia Breakup during Reentry," Columbia Accident Investigation Board (CAIB) Report Volume II D.16, 2003.

${ }^{21}$ Baeker, J., Cavalli, J. R., and Morris, M., "Downrange Overflight Risk Analysis Methods for Space Shuttle Launches," AIAA Atmospheric Flight Mechanics Conf., San Francisco, CA, 2005.

${ }^{22}$ Champaigne, K. D. and Sumners, J., "Low-power Electronics for Distributed Impact Detection and Piezoelectric Sensor Applications," IEEE Aerospace Conf., 2007.

${ }^{23}$ Studor, G., "JSC Micro-Wireless Instrumentation Systems on Space Shuttle and International Space Station," CANEUS Workshop, Toulouse, France, 2006.

${ }^{24}$ Studor, G., "Fly-by-Wireless: A Revolution in Aerospace Architectures for Instrumentation and Control," NASA/CANEUS Workshop, Grapevine, TX, 2007.

${ }^{25}$ Iverson, D. L., "System Health Monitoring for Space Mission Operations," IEEE Aerospace Conf., Big Sky, MT, 2009.

${ }^{26}$ Iverson, D. L., Martin, R., Schwabacher, M., Spirkovska, L., and Taylor, W., Mackey, R. and Castle, J. P., "General Purpose Data-Driven System Monitoring for Space Operations," AIAA Infotech@Aerospace Conf., Seattle, WA, 2009.

${ }^{27}$ Kaul, U. K., "Idealized Modeling and Analysis of Shuttle Wing Leading Edge Impact Data," SAE AeroTech Congress \& Exhibition, Los Angeles, CA, 2007.

${ }^{28}$ Gabrys, J., Schatz, J., Carney, K., Melis, M., Fasanella, E. L., and Lyle, K., "The Use of LS-DYNA in the Columbia Accident Investigation and Return to Flight Activities," The 8th International LS-DYNA Users Conf., 2004.

${ }^{29}$ Bohr, J., "Preparation and Support of a Tap Test on the Leading Edge Surfaces of the Space Shuttle," SEM Winter Test and Measurement Conf., Mesa, AZ, 2009.

${ }^{30}$ Madaras, E. I., Winfree, W. P., Prosser, W. H., Wincheski, R. A., and Cramer, K. E., "Nondestructive Evaluation for the Space Shuttle's Wing Leading Edge," The 41st Joint Propulsion Conf. \& Exhibit, Tucson, AZ, 2005.

${ }^{31}$ Hasselman, T., Yap, K., Wathugala, G., and Anderson, M., "A Top-down Method for Uncertainty Quantification and Predictive Accuracy Assessment”, The 46th Structures, Structural Dynamics, and Materials (SDM) Conf., Austin, TX, 2005.

${ }^{32}$ Yap, K. C., Wathugala, G. W., and Hasselman, T. K., "An Updated Toolbox for Validation and Uncertainty Quantification of Nonlinear Finite Element Models," The 7th International LS-DYNA Users Conf., Dearborn, MI, 2002.

${ }^{33}$ Yap, K., Hasselman, T., and Cafeo, J., "Uncertainty Quantification Applied to Predictive Accuracy Assessment for Numerical Car Crash Simulations," The 21st International Modal Analysis Conf. (IMAC), Orlando, FL, 2003.

${ }^{34}$ Hasselman, T., Yap, K. C., Cafeo, J., and Lin, C-H, “A Case Study in Model Improvement for Vehicle Crashworthiness Simulation," The 23rd IMAC, Orlando, FL, 2005.

${ }^{35}$ Lear, D., Christiansen, E., Hyde, J., Herrin, J., Lyons, F., Kerr, J., and Ryan, S., "Investigation of Shuttle Radiator MicroMeteoroid and Orbital Debris Damage," The 50th SDM Conf., Palm Springs, CA, 2009.

${ }^{36}$ Hyde, J. L., Christiansen, E. L., Lear, D. M., and Kerr, J. H., "Space Shuttle MMOD Threat Mitigation Techniques," The 59th International Astronautical Congress, Glasgow, UK, 2008.

${ }^{37}$ Urbina, A., Paez, T. L., Hasselman, T. K., Wathugala, G. W., and Yap, K. C., "Assessment of Model Accuracy Relative to Stochastic System Behavior," The 44th SDM Conf., Norfolk, VA, 2003.

${ }^{38}$ NASA, "Micrometeoroid and Orbital Debris (MMOD) Protection," ISS - An Interactive Reference Guide, 2010.

${ }^{39}$ Trott, A., "Wireless Instrumentation - New Technology Development and Applications," JANNAF 4th Space Vehicle \& Propulsion Systems Wireless Sensors Workshop, Orlando, FL, 2010.

${ }^{40}$ Wilson, W. C., Perey, D. F., Atkinson, G. M., Barclay, R. O., "Passive Wireless Surface Acoustic Wave Sensors for Integrated Vehicle Health Monitoring," IEEE International Frequency Control Symposium, Honolulu, HI, 2008.

${ }^{41}$ Trelewicz, J. R., Gutleber, J., Gouldstone, C., and Brogan, J. A., "Direct Write Sensors for Health Management of Composite Aerostructures," The 55th International SAMPE Symposium, Seattle, WA, 2010.

${ }^{42}$ Park, G., Rosing, T., Todd, M. D., Farrar, C. R., and Hodgkiss, W., "Energy Harvesting for Structural Health Monitoring Sensor Networks," Journal of Infrastructure Systems, Vol. 14, No. 1, pp. 64-79, 2008. 